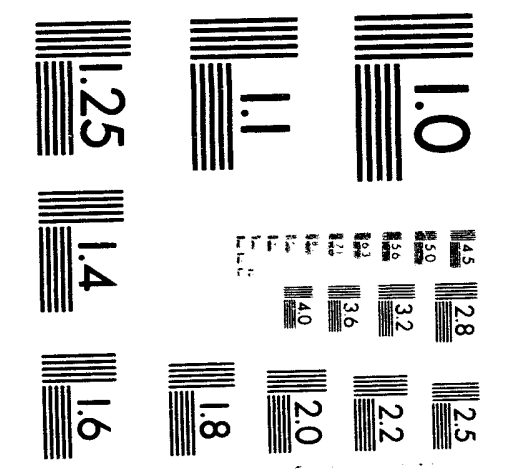



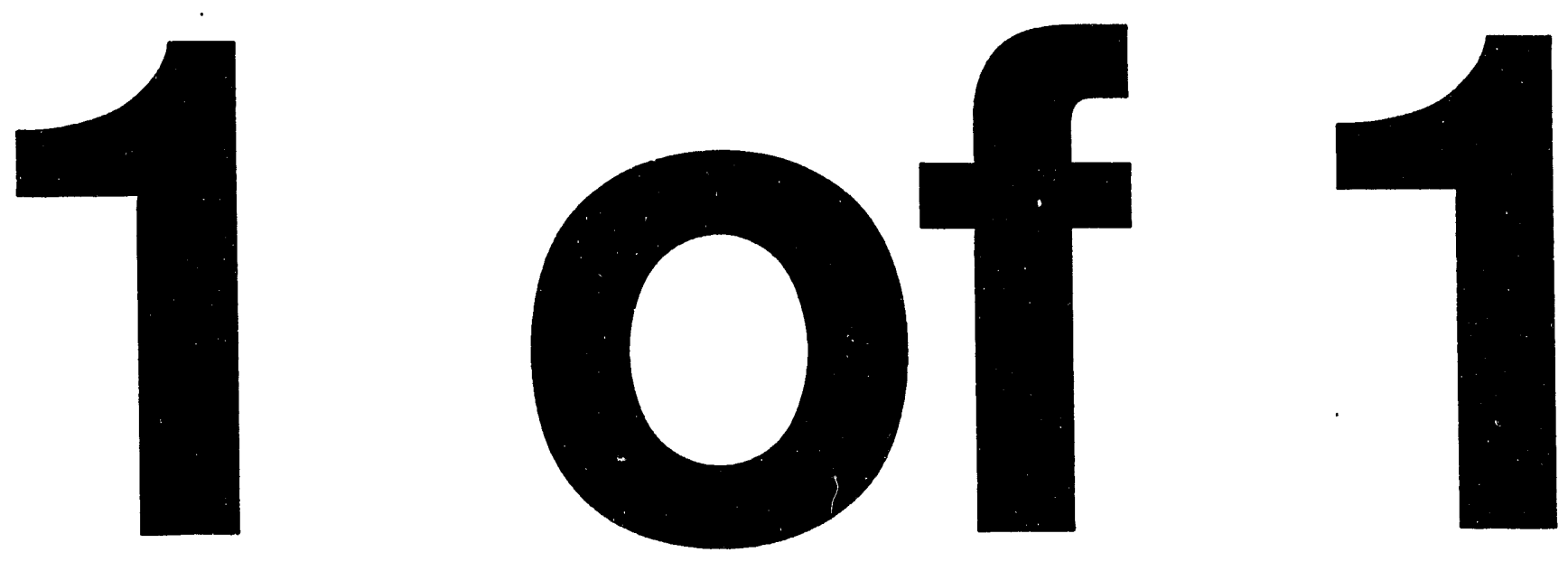


\section{TECHNICAL REVIEW OF SRT-CMA-930058 REVALIDATION STUDIES OF MARK 16 EXPERIMENTS: J70}

by

Raymond L. Reed

Westinghouse Savannah River Company

Savannah River Site

Aiken, South Carolina 29808

This paper was prepared in connection with work done under the above contract number with the U.S. Department of Energy. By acceptance of this paper, the publisher and/or recipient acknowledges the U.S. Government's right to retain a nonexclusive, royalty-free license in and to any copyright covering this paper, along with the right to reproduce and to authorize others to reproduce all or part of the copyrighted paper. 


\section{DISCLAIMER}

This reporn was prepared as an account of work sponsored by an agency of the United States Government. Neither the United States Government nor any agency thereof, nor any of their employees, makes any warranty, express or implied, or assumes any legal liability or rf sponsibility for the accuracy, completeness, or usefulness of any information, apparatus, product, or process disclosed, or represents that its use would not infringe privately owned rights. Reference herein to any specific commercial product, process, or service by trade name, trademark, manufacturer, or otherwise does not necessarily constitute or imply its endorsement, recommendation, or favoring by the United States Government or any agency thereof. The views and opinions of authors expressed herein do not necessarily state or reflect those of the United States Government or any agency thereof.

This report has been reproduced directly from the best available copy.

Available to DOE and DOE contractors from the Office of Scientific and Technical Information, P. O. Box 62, Oak Ridge, TN 37831; prices available from (615) $576-8401$.

Available to the public from the National Technical Information Service, U. S. Deparment of Commerce, 5285 Por Royal Rd., Springfield, VA 22161 


\section{SAVANNAH RIVER TECHNOLOGY CENTER}

\section{Applied Technology Section}

SRT-CMA-930073

\section{Applied Physics Group}

October 25, 1993

KEYWORDS:

Technical

Criticality

UNCLASSIFIED

DOES NOT CONTAIN JHCLASSIFIED

Computer Codes

CONTROLLED NUCLEAR INFORMATION

Validation

ADC \&

REVIEWING

OFFICIAL

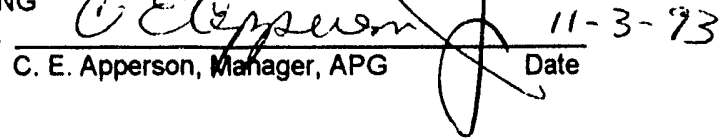

RETENTION:

PERMANENT

\section{TECHNICAL REVIEW OF SRT-CMA-930058} Revalidation Studies of Mark 16 Experiments: J70 (U)

Author

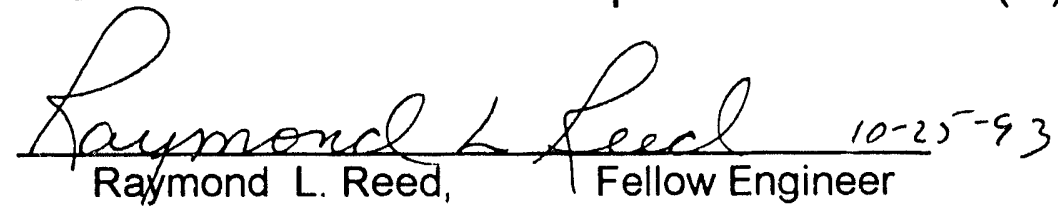

APPROVALS

Task Leader

APG Criticality Methods and Analysis

Manager

Applied Physics Group (APG)

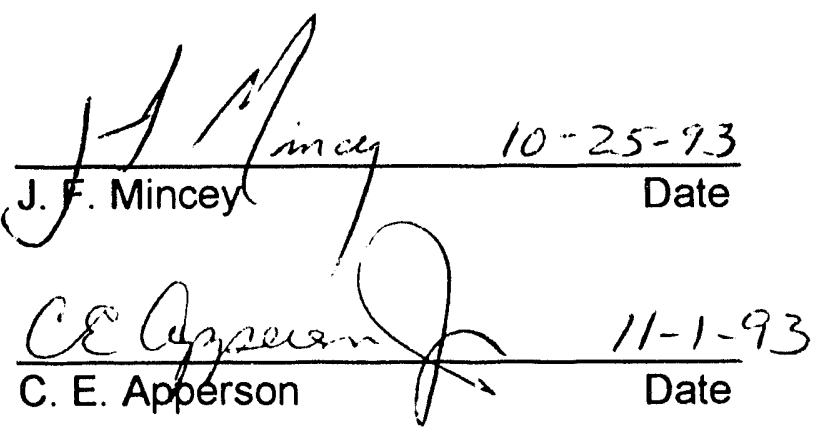

Distribution:
M. R. Buckner,
$773-42 A$
C. E. Apperson,
J. F. Mincey,
$773-22 A$
S. Y. Lee,
$773-11 \mathrm{~A}$
R. L. Reed,
$773-42 A$
R. L. Webb,
$786-1 A$
E. F. Trumble,
786-1A

$\begin{array}{ll}\text { T. G. Williamson, } & 773-42 A \\ \text { P. L. Vescovi, } & 773-22 A \\ \text { R. E. Rathbun, } & 786-1 \mathrm{~A} \\ \text { M. A. Rosser, } & 705-\mathrm{K} \\ \text { T. A. Reilly, } & 707-\mathrm{F} \\ \text { APG Files, } & 773-42 \mathrm{~A}\end{array}$

Technical Information Management, 703-43A 


\section{INTRODUCTION \& SUMMARY}

This study (Reference 1 ) is a reperformance of a set of MGBS-TGAL criticality safety code validation calculations previously reported by Clark (Reference 2 ). The reperformance was needed because the records of the previous calculations could not be located in current APG files and records. As noted by the author, preliminary attempts to reproduce the Clark results by direct modeling in MGBS and TGAL were unsuccessful. Consultation with Clark indicated that the MGBS-TGAL (EXPT) option within the KOKO system (Reference 3) should be used to set up the MGBS and TGAL input data records.

The results of the study indicate that the technique used by Clark has been established and that the technique is now documented for future use. File records of the calculations have also been established in APG files.

The review was performed per QAP II-14 of 1Q34 (References 4 and 5). Since the reviewer was involved in developing the procedural technique used for this study, this review can not be considered a fully independent review, but should be considered

- $\quad$ a verification that the document contains adequate information to allow a new user to perform similar calculations,

- $\quad$ a verification of the procedure by performing several calculations independently with identical results to the reported results, and

- a verification of the readability of the report.

\section{DISCUSSION}

The MGBS-TGAL (EXPT) option in KOKO expects the INPUT.KOKO.MGEX.?NAME.?N record. KOKO converts the relatively basic and simple input of that record, describing a uniform array of fuel assemblies in water, into detailed MGBS and TGAL input records. KOKO also performs automatically and consistently the many tedious calculations required to provide the MGBS and TGAL input data. If not performed by KOKO, such calculations must be performed by hand by the user preparatory to MGBS record preparation. Such calculations include the calculation of fuel tube contents (uranium isotopes and aluminum) in g/cc given only the $235 \mathrm{U}$ loading (gm/ft) and uranium isotopics (\%). KOKO also specifies all options found most applicable to criticality calculations. Having allowed KOKO to generate the MGBS and TGAL records and calculate a reactivity for the uniform array, the user, for cases not fully represented by the uniform array, can easily modify the TGAL input records to model the array accurately, including presence of poison regions in the array. 
The review consisted of

- a careful reading of the draft document and reference documents,

- examination of consistency of numerical values reported in the draft document with data provided in reference documents and the calculations,

- extensive discussion with the author of editorial comments to improve the document readability,

- $\quad$ review of the microfiche output for each calculation reported in the report to verify input data agreement with Clark's document and accurate iranscription of calculated results, and

- independent calculations of several cases reported in the document following the procedure specified in the document, incorporating the physical and experimental data specified in Clark's document (and included in the reviewed document).

The independent calculations were performed for cases other than those provided as examples in the report and resulted in the same answers as reported in the document. Those calculations are not detailed here, but the microfiche output (Jobs 458, 459, and 464) are available in APG files (referenced to this review document).

The report is not intended to be an NCSE as defined by WSRC-IM-93-13 (Reference $6)$.

A draft copy of the report is not included in this review document since :

- many editorial changes have been made to the report during the review process,

- $\quad$ the report is long (29 pages), and

- a copy of the report will be maintained in APG files in addition to site files.

\section{SUMMARY AND CONCLUSIONS}

A technique of using the KOKO module and the associated criticality code modules MGBS and TGAL has been established that essentially reproduces the results reported by Clark for MGBS-TGAL calculations of experimental lattices. The procedure has been described in sufficient detail, with example calculations, to enable a new user to model similar lattices using the criticality safety modules. The report established equivalence of results with Clark's reported results. 


\section{REFERENCES}

1. S. Y. Lee, "Revalidation Studies of Mark 16 Experiments: J70 (U"), SRT-CMA-930058, Draft (10/21/93)

2. H. K. Clark, "Correlations with Mark 16 Experiments", DPST-83-1025, November 29, 1983

3. H. K. Clark, Users's Manual, JOSHUA Nuclear Criticality Safety Modules, DPSTM-86-700-3, March, 1987

4. MANUAL 1Q34, NRTSC QUALITY ASSURANCE MANUAL, January 1991

5. NRTSC QA Procedure QAP \|-14, "TECHNICAL REVIEW", August, 1991

6. WSRC-IM-93-13, WSRC Nuclear Criticality Safety Manual, Revision 1, July 1, 1993 
OSR 24-K7

\section{NRTSC REVIEW SHEET}

TASK TITLE REVALIDATION STUDIES OF MARK 16 EXPERIMENTS: $J 70$

TASK NUMBER_ N/A

ITEM REVIEWED SRT-CMA-930058

PAGE 1 OF 1

(Attach additional pages as necessary; marked-up pages are acceptable.)

\section{Areas reviewed (identify clearly each area reviewed).}

Logic of presentation

Clarity of presentation

Accuracy of presentation

Applicability of presentation

Consistency of data values referenced to reference values

Usability of the procedure presented

\section{Approaches used to perform the review.}

Read the document carefully.

Read the references carefully and ensured data values were accurately repeated.

Performed calculations per the indicated procedure.

Ensured the readability of the presentation and agreement of intent with material as presented.

Extensively discussed editorial variances and readability with author

3. Questions, comments to be resolved.

$\mathrm{X}$ I agree with the technical content I disagree with the technical content.

$\mathrm{X}$ I accept the conclusions and recommendations

I do not accept the conclusions and recommendations for the following reasons:

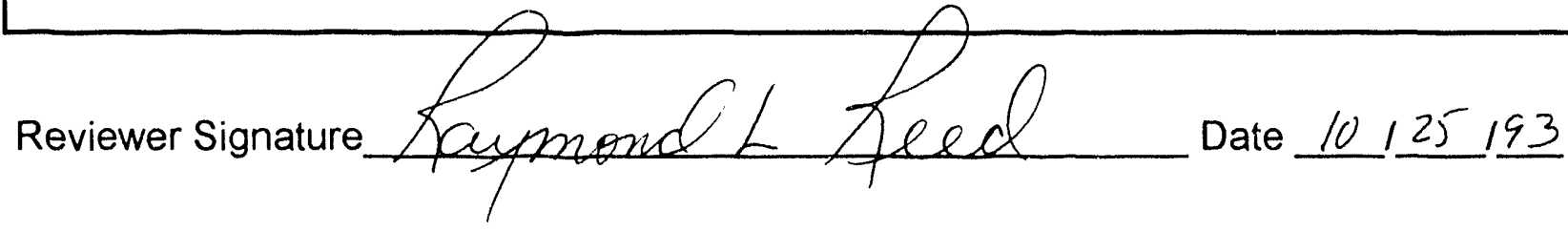



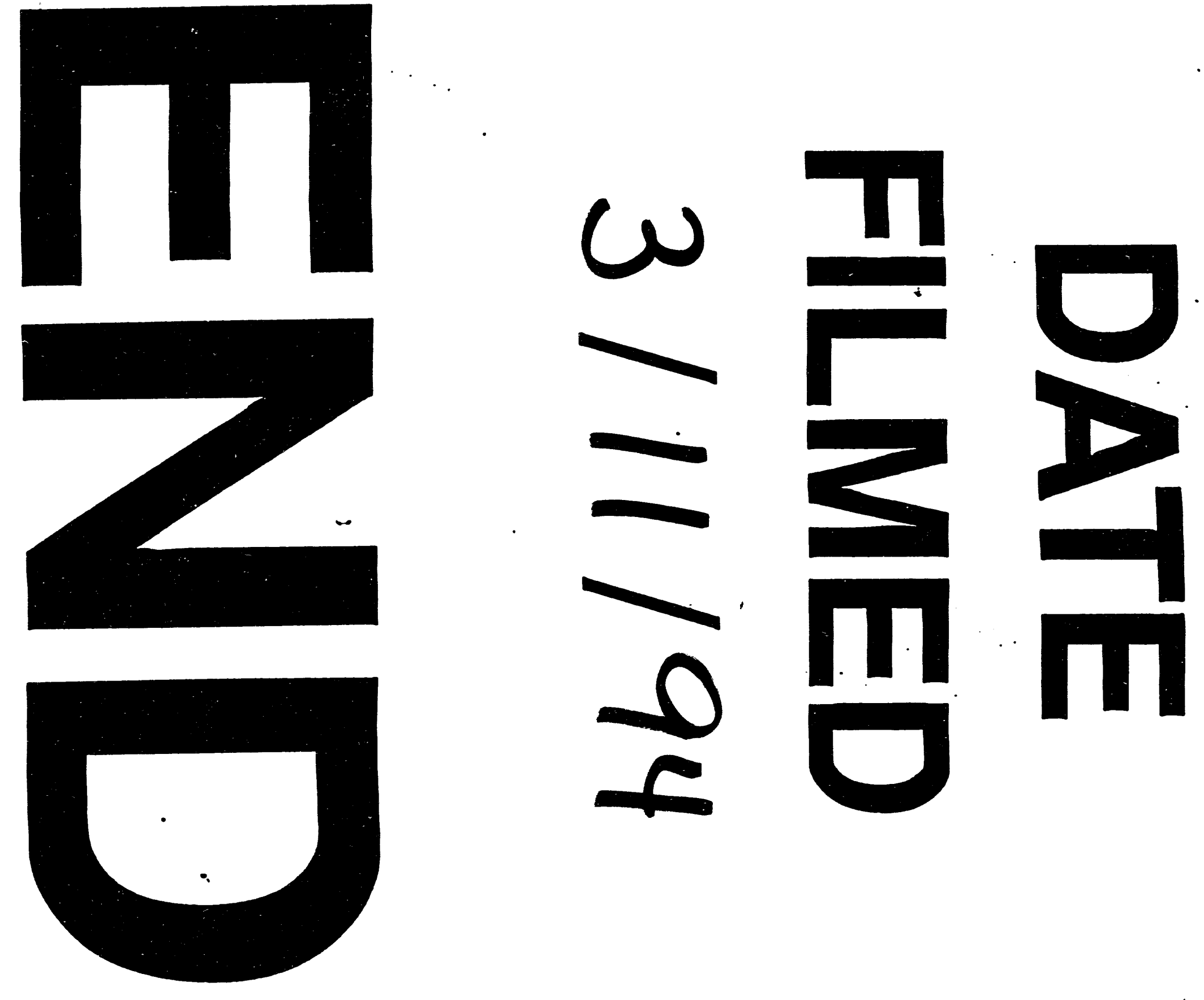
